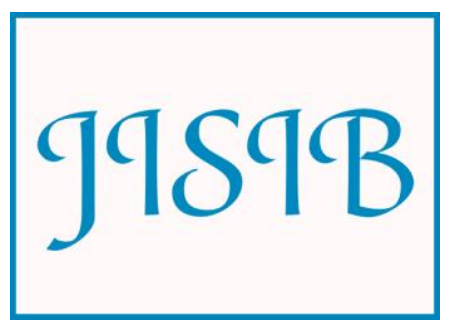

Available for free online at https://ojs.hh.se/

Journal of Intelligence Studies in Business 3 (2012) 12-28

\title{
How to adapt a tactical board wargame for marketing strategy identification
}

\author{
Stéphane Goria \\ Université de Lorraine, CREM Laboratory, \\ Département Informatique, IUT Nancy Charlemagne, \\ 2 ter boulevard Charlemagne - CS 55227, \\ F-54052 Nancy, FRANCE \\ stephane.goria@univ-lorraine.fr
}

\begin{abstract}
This research paper investigates some fundamental principles of marketing warfare to see specifically what kinds of maneuvers can be used to defend or take control of a certain market. We present military wargames and its history to ease the understanding of the fundamentals in this area of study. Since we did not find a visual business wargame solution for our problem in the literature, we decided to develop one, based on the French market of game consoles between Nintendo and Sony in the period between 1994 and 2010. Our experiment confirmed the value of wargaming. It showed that a parallel could be made between tactical maneuvers on the map and the statistics of sales for this market during the time interval.
\end{abstract}

KEYWORDS: Wargames, marketing warfare, board wargames, Competitive Intelligence, game consoles

\section{Introduction}

In order to be competitive or simply to survive, companies have to choose strategies which incorporate development. Innovation is a common solution for many of them (Trot 2008, 77-78) (Lundvall 2010,328 ). But innovating is always risky, because one can't know if strategic orientation of innovation will be good before the new product or service will be on market. Another approach concerns quality methods which often propose some solutions to perform a company process (Weaver 1991) (Pyzdek and Keller 2003). But, these take a long time for implementation and need organizational involvement. In addition, they work in a homogeneous way and consequently their impact is homogenous too and easily predictable. Another choice is proposed by marketing warfare (Kotler and Singh 2001). With this approach called war analogy, the authors propose to elaborate company strategic planning, according to war laws and the position of the company in its markets. But till now, marketing warfare is reduced to abstract analogies and it is not easy for the most part to envisage a company strategy with only abstractions. A partial response to this is proposed by a business wargame approach. From war and battle models for military strategies development, some researchers have tried 
to fit them to markets (Herman et al. 2009) (Gilad 2009). This approach gives some keys about how to simulate a competitive environment and shows the first interest for competitive intelligence (Kurtz and Schuller 2008) and economic intelligence (Besson et al. 2010). Nowadays it is also considered a marketing intelligence analysis tool (Jenster and Søilen 2009, 165), for a warning system (Gilad 2003, 93) or as an accelerator for decision-making processes with the capability to anticipate the future (Fuld 2003) (Cares and Miskel 2007). However, in our opinion this approach has a drawback: it doesn't propose, as its military cousins, visual systems to identify and consider marketing warfare maneuvers. For some time the competitive intelligence community has also been interested in information visualization tools for their applications (Shaker and Gembicki 1998, 130) (Bose 2008) (Besson et al. 2010, 122). We can assume that visual application for wargaming will improve the use of competitive intelligence. With this assumption, the wargames become tools for more creative competitive intelligence, i.e. a kind of competitive intelligence where we use creative techniques to stimulate the imagination of decision-makers and analysts with the aim to identify opportunities and threats. In this paper, we try to solve this problem of how to display information to propose a solution for marketing warfare maneuvers with visual presentation in real competitive context. We base our work on information clarifying in relation to, first marketing warfare theories, and second, on wargame history and solutions and, in third, how to propose a visual representation of war analogy with visual tools already developed for this purpose with board wargames. Finally, we present our methodology to transform market or product information in a tactical board wargame. To illustrate this, we created a map using home video game consoles battles, with Sony and Nintendo from 1995 to 2007.

\section{Marketing warfare}

By analogy with the war, marketing warfare is based on the idea that many competitive situations can be interpreted in terms of war strategies. In the beginning of 1980s (Kotler and Singh 2001) and (Ries and Trout 2006, 44) researchers proposed to consider the mind of a consumer as a battleground. Then, they interpreted the company strategies possible in four categories: (1) defensive, (2) offensive, (3) flanking attack and (4) guerrilla. In the case of (Kotler and Singh 2001) there are two flank/flanking attacks ${ }^{1}$ (figure 1): simple and bypass (a bypass attack wins the battle by attacking

\footnotetext{
${ }^{1}$ In marketing warfare, it seems the "flanking attack" expression is preferred to "flank attack"; but for military terminology, it seems different. In this paper, when we talk about marketing warfare, we use "flanking attack" and when we talk about military battle we use "flank attack".
}

not defended zones). For (Ries and Trout 2006, 83) bypass attacks are not accurate and encirclement attack is included in the flanking option. They also add which strategy is good for which company:

- Defending option suits the market leader. It implies than all strong competitive moves should be blocked and the best defensive strategy is the courage to attack oneself.

- Direct offensive option suits the number 2 company on the market. It implies that we consider the strength of the leader's position to find a weakness in the leader's strength and attack at that point. We then launch an attack on a front as narrow as possible.

- Flanking option suits smaller companies. It implies tactical surprise, an oriented attack into an uncontested area. We follow the pursuit attack to its end.

- Guerrilla option suits local and regional companies. It implies that these companies try to find a market segment small enough to defend. They will never act like the leader and be prepared to run away at any time. 


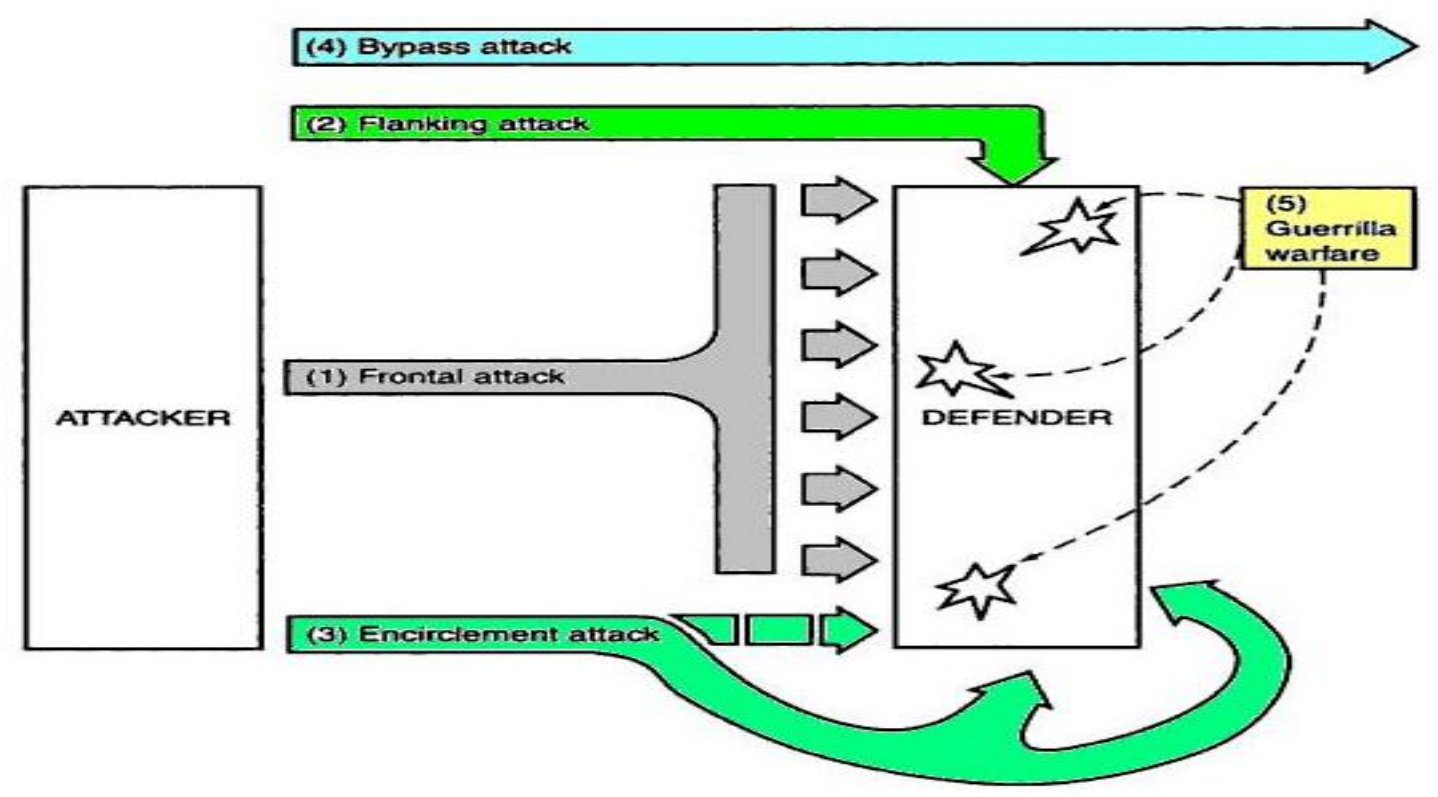

Figure 1: Attack alternatives in marketing warfare (Kotler and Singh, 2001)

However, these propositions seem to be lacking on strategic and tactical attack and defence warfare levels. For example, guerrilla warfare is a type of warfare and not really kind of attack. To respond to this problem (James 1985, 7) proposed 4 kinds of strategic maneuvers: deterrent, attack, defence and alliance: "Deterrent strategies in business attempt to induce stability by encouraging prudence on the part of competitors" (James 1985, 31). Attack and defence strategic manoeuvres contain each a set of tactical maneuvers. Attack includes (Kotler and Singh 2001) alternatives and isolation and unconventional offense. Unconventional offense is a kind of interpretation for guerrilla tactics when guerrilla forces look for a local superiority to strike the enemy and retreat. Isolation alternative is a specific proposition (James 1985, 60). With this tactic, the enemy's strong points "are bypassed by main forces and mopped up by later waves of troops or left to surrender". Tactical defence maneuvers include: position defence (intensification of its positions), mobile defence, pre-emptive strike, flank positioning (reinforcing flanks), counter offensive and withdrawal.

But, for all of these propositions, marketing warfare doesn't suggest a less metaphoric interpretation of maneuvers. The only system proposed is a reference to market segmentation. It is interesting, but too abstract to interpret a situation in terms of attack or defence alternatives. To apply this idea people need to imagine battleground and armies' positions. In fact, at a tactical level, marketing warfare seems have no solution to guide our interpretation of clash actions_and battle orders. At this level, marketing warfare is a kind of philosophy to consider as we see to manage a market situation. Another criticism of marketing warfare is the frequent use of some innovative solutions to illustrate it without a real place for innovation in the strategy. For Ries and Trout $(2006,58)$ attacking yourself is an innovative element in a manoeuvre to attack or defend a position (examples used are Starbucks coffee, Gillette razors and iPod). However, they don't give any information to identify a kind of efficiently in these cases. To find this information, to include innovation with more guidance in marketing warfare strategy, we looked into the innovation literature and specifically into the buyer utility map (see 4.1 ).

\section{Wargame proposition}

Wargame is a tool made to consider a war situation with many possibilities of development. It helps the decision-maker to envisage his choices and those of the opponent. "The object of any wargame (historical or otherwise) is to enable the player to recreate a specific event and, more importantly, to be able to explore what might have been if the player decides to do things differently" (Dunnigan 2000, 1). Its recent history can already look back at two centuries of military applications and around sixty years of applications in business. Wargames propose different options to consider war situations from the skirmish level to strategic level including the tactical level. 


\subsection{A brief history of wargames}

It is difficult to date the origin of wargames. Most authors give an origin around the 7th century BC. The two traditional ancestors of wargame are the Game of Go and the Chess, respectively: Wei Hei from China and Chaturanga from India. Personally, we add to these two ancestors three other forgotten abstract games with similar rules: Petteia ${ }^{2}$ (Greece), Seega (Egypt) and Latrunculorum (Rome), which appeared around the 5th century BC. From these very abstract war or battle representations, other kinds of war game appeared. One was Metromaxia, a Chess evolution which presents around 1578, a medieval battle simulation between two armies and two castles, and a resolution of the battles based on mathematics (Boutin and Parlebas 1999). Some years later, a battleground simulation appeared in Prussia. In 1644 C. Weickhmann created the Koenigsspiel (King's game). It's a game derived from Chess: a first "War Chess" model including a board bigger than usual and thirty tokens for each player. One century later, in 1779 , J. Clerk proposed a simulation of naval engagement, perhaps the first naval wargame (Perla 1990, 20). This game used small wooden tokens to represent combat actions between warships with rules including geometry and mathematics to solve firepower effects, ship maneuvers and wind effects. Admiral G.B. Rodney tested new tactics studied with Clerk's wargame and validated them with his victory in the Battle of Saintes (1782). We may say that modern wargame history begun at this time. In 1780, C.L. Helwig modified War Chess to transform them into a modern wargame. He extended the game board to a
Venturini's game and rules included a calculation system to quantify the combat effects of different types of units (Perla 1990, 28). After a first failure to propose this game to teach war principles to young Prussian officers, the game modified by the son was later adopted by the Prussian army. We notice than some years later, in Prussia, two conceptions of kriegspiel (wargames) are defended: the rigid kriegspiel, based on statistics and calculations for movement and engagement resolution with lots of detailed rules, and the easier and faster free kriegspiel, where troops' capacities are based on umpire interpretations according to the context. Prussian and German victories of the second half of 19th century contributed to develop both wargame systems in others countries (for example USA, UK, Japan). Later the evolution of wargames continued to be made in the USA. First, Lieutenant C.A.L. Totten published in 1880, Strategos: a serie of American games of war based upon military principles. This game was designed for history fans and is one of the first wargames dedicated to civilians. Totten contributed in wargame development with the reintroduction of squares on the board with a topographic square grid map to simplify movement calculation (Patrick 1977). Second, Major W.R. Livermore edited in 1882 The American kriegspiel, a game for Practicing Art of War upon a Topographical Map, a translation of the rigid German kriegspiel. From Livermore, tokens are often counters with specific informations marked above (see figure 2). This solution helps the facilitated use of rigid wargames.

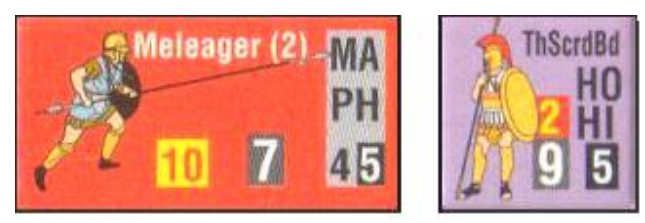

Figure 2: Two counters for a board wargame (Great Battles of Alexander, GMT Games)

1666 squares board, using coloured squares to represent ground variations (forests, rivers, mountains, ...) which have an impact on the tokens' movements. He also proposed the aggregation concept: "employing a single playing piece to represent a large body of soldiers or organized combat units" (Perla 1990, 18) and, he included an umpire to supervise the play (to decide in case of ambiguities). Right after, in 1797, Georg Venturini adapted Clerk's game with topographic maps (battleships were removed and replaced by battalions). We can say that modern wargame matured in Prussia with the invention of kriegspiel (literally wargame) with the contributions of Von Reißwitz, father and son, between 1811 and 1824 . The game used a map like

\footnotetext{
${ }^{2}$ http://www.di.fc.ul.pt/ jpn/gv/petteia.htm
}

After Totten's works, civilians quickly adopted wargames for their own use and special problems. The hobby of wargame was developed in two types: board wargames (with counters and a map) and wargames with miniatures (little tin soldiers or vehicles) initiated by H.G. Wells's game: Little wars in 1912. However, the true wargame hobby development first appeared after the Second World War. In 1958 Avalon Hill created a company dedicated to wargame_edition for civilians. The company's creation was followed by many others during the years 1960-1990. Concerning the application of wargames to business, it seems that its beginning is linked to military electronic wargaming development. During the Second World War, computers and electronic calculators were developed. In 1958, the Navy announced the development of NEWS 
(Navy Electronic Warfare Simulator). Then, the same year (Andlinger 1958) proposed a kind of business wargame to the consulting firm McKinsey \& Company (Faria and Nulsen 1996).

\subsection{Wargame applications to business}

From the application to markets and business, wargames are generally called or known as "business wargames". In these variations (Kurtz 2003) (Gilad 2009, 17) (Oriesek and Schwarz 2008, 22), the business wargame is a kind of role-playing game applied to a competitive environment. From the 1970s (Kalman and Rehnman 1975) the business wargame is thought of as played by a set of teams (2 to 6), often associated with a complex computing simulation of a market and a set of scenarios. The role-playing simulation in competitive business situations with a computing model can be linked to either a rigid business wargame and those without a simulation, which are simplest to manipulate, can be linked to the free business wargame (Gilad 2009, 19). A business wargame takes around 6 weeks to 12 weeks to play for the rigid versions (Herman et al. 2009, 15) and 1 to 2 days for the free versions (Gilad 2003, 90).

The phases in a business wargame often follow along the lines of this model (Oriesek and Schwarz 2008, 119):

1. Design: objective and requirement definition, interview with senior management;

2. Preparation: game book conception, market and control models development, pre-tests;

3. Execution: team motivation, run the wargame;

4. Debriefing and documentation: documentation about lessons learned and implications for next steps strategy realizations.

Unfortunately, in these cases of wargames used for a market, we didn't find a real visual map to identify competitive maneuvers. The only option used seem to follow along the lines of a monopoly board (Schwartz and Teach 2002). This type of presentation leaves much to be asked for as compared to the more advanced military wargames. This is why we in this research turned to the wargame hobby and in particular to board wargames, in order to find a more interesting and useful presenta- tions for our problem which could include a more dynamic play.

\subsection{A board wargame presentation}

A board wargame usually includes five types of elements: (1) a map, (2) counters or other pieces representing units, (3) rules, (4) a few player aid cards and (5) a set of scenarios.

Nowadays, there are essentially three kinds of maps for board wargame: geomorphic, geographical and point-to-point. Geomorphic maps are mostly hexagonal grid maps (an Avalon Hill Company creation). These maps are generally used for tactical level games. Geographical area maps are maps where counters are put on areas identified with others by a frontier. Point-to-point system maps use mostly some intersection, generally communication ways to put the counters on. On a map some particular context elements can be shown, like ground variations. Geographical and point-to-point maps are generally used for strategic level games. Size of map depends on the game, but generally is displayed on a sheet around $17 * 22$ " to $22 * 34$ " $(43.2 * 55.9 \mathrm{~cm}$ to $55.9 * 86.4 \mathrm{~cm}$ or $\sim \mathrm{A} 2$ to A1 page format).

Shape of the counters (like in figure 2) is mostly square or double squares. Simonen (1977) specified that the standard counter size is $13.86 \mathrm{~mm}(\sim 0.54$ ") for a map with standard hexagons of a diameter of $16 \mathrm{~mm}(\sim 0.63 ")$. Counters are designed to present important information for the game. On each counter, a set of data is displayed according to its relative importance. An order and a code (position on the counter and a specific colour) to represent items on counter is chosen to identify one from another. Simonen (1977) presents a list of questions to display items on a counter:

1. Who owns the counter?

2. What type of counter is it?

3 . What is the primary value(s) of the counter?

4. What historical or functional information not included in above categories is necessary for the play of the game?

5. What historical information not included in categories above is desirable to display on the counter even though the information is not functionally necessary? 


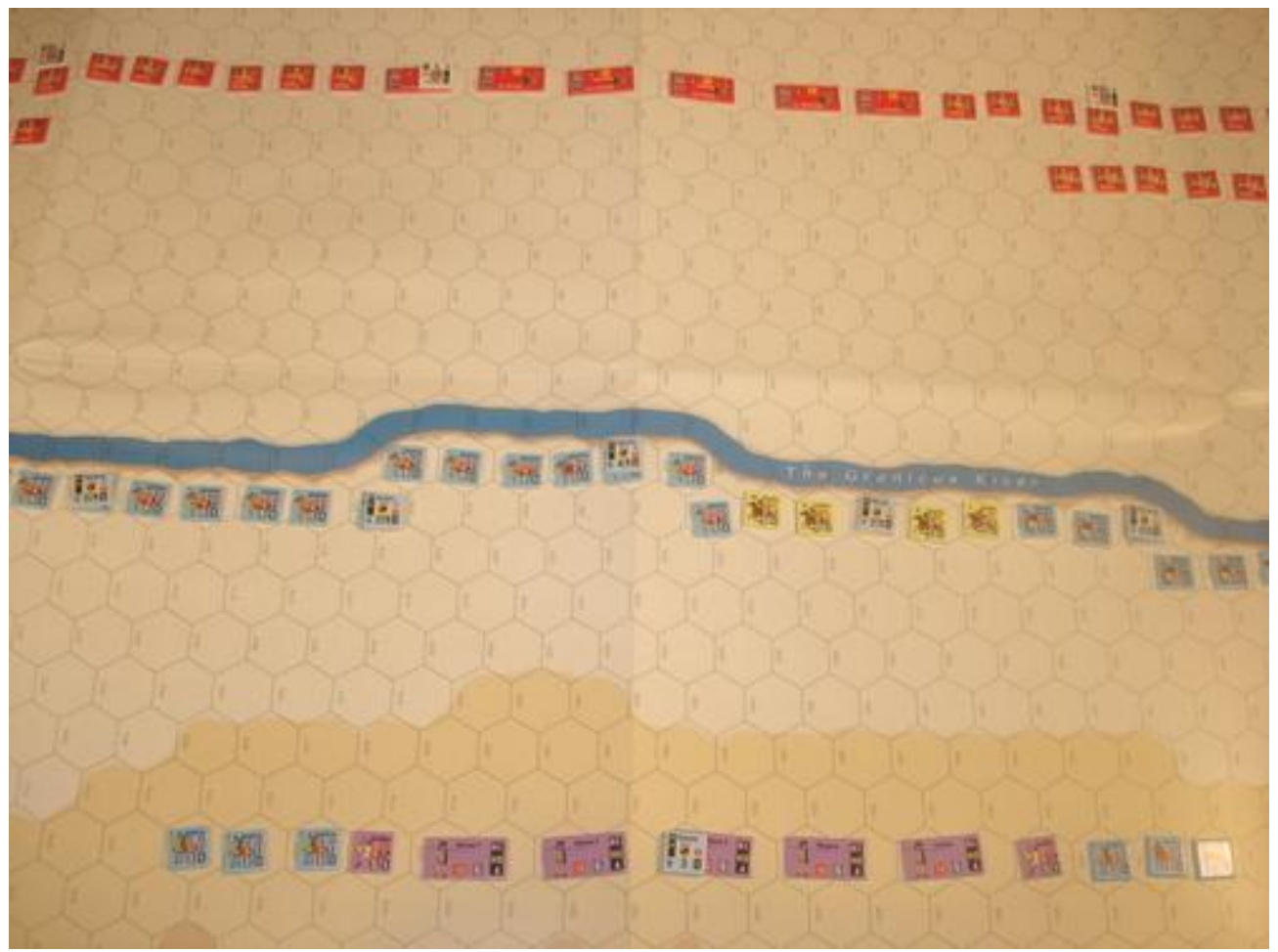

\section{Figure 3: Great Battles of Alexander (GMT Games) board wargame map with armies to represent the Battle of} Granicus River

Counters represent most of the time military units or others special elements like unit leaders. To help identification of units, units of the same origin (country or army) are represented with counters of the same colour. In addition, to solve ambiguities in case of a large set of counters, their origin is written on the counter. For the same consideration, the type of unit or leader is displayed with an abbreviation associated with an image representing the unit or the personage.

Rules explain the historical considerations, the representation scale chosen, items displayed on a counter, sequences of play, and a system to solve engagements and movements (notably, in function of units, types and terrain variations). Rules usually include charts to help players solve most of situations in the game. These charts are often offered in the shape of player handouts.

Finally, a set of scenarios propose some ways to play the game and to consider the historical vision of the game designers. A scenario includes army battle orders (i.e. the positions of units on the map at the beginning of the game), objectives of each army, the duration of the game (or number of game rounds), and a system (victory point calculation) for how to know who has won at the end.

\section{Method: From marketing warfare to board wargame representations}

After some discussions with managers and others decision makers, we noticed that marketing warfare notions are too abstract for many. Even though, they accept and approve some of the marketing warfare considerations, it is difficult for users to apply them easily to their business. In fact, we had a problem to visually represent marketing warfare concepts. Another problem with marketing warfare applications seemed to be the development of how to support attack or defend the strategy of a company. At this moment, we looked for tools and we were interested in the buyer utility map (see chapter 4.1). But, with this tool to help orientate a strategy, we had no solution for the other marketing warfare concepts. As marketing warfare is a war analogy for marketing, we looked for solutions in the field of board wargames. Without a real solution, but with some idea of board representation, we then developed our own solution.

Following the order in which elements included in a wargame were presented, we began with the map. In marketing warfare the prospect or consumer mind is the battleground. We have proposed a very simple solution that anybody can use, understand and modify according to the context or point of view. With tactical board wargames we have considered which elements permit us to understand a battle in terms of maneuvers. Board wargames seemed to be the best for this problem (figure 3). Like in marketing warfare, we decided that the battleground is the consumer's mind, from his point of view, as he interprets a product or a service valuelinterest. 


\subsection{Tactical wargame considerations}

We considered all components of a current tactical board wargame to transform it into a product or service board wargame presentation. First, we decided that tactical wargame maps (geomorphic maps) make a good representation of the objectives. These maps (square grid maps or hexagon grid maps) are practical to define the positions of units and to calculate movements. But, with maps it is à priori difficult to determine the front line. This is why we thought that, like in Chinese chess, a river can be very practical for delimitating the front line (figure 3). We also had an idea of the shape of the battle maps that we wanted.

Second, we tried to define counters. In a wargame, counters represent army unities. In marketing warfare, armies are companies. For our objective, counters should represent a company unit for a particular market from a consumer point of view. Thus, we opted to make counters with a particular colour and a representation relatively to each company.

Then there is the question of what these counters can represent and how they can be placed on the board and move on the map. In wargames, this is developed in a scenario at units scale, along with the order of battle and the rules for movements. This implied that we have some equivalent consideration for marketing warfare representations. With a classical market segmentation grid, most parameters chosen are not ordered except for some of them, like age categories. We want units to be able to move on the map. With a counter corresponding to a classical interseption in a market segmentation grid, it is difficult to simulate few coherent movements with regard to time. However, if we consider à priori a counter movement and link it to the consumer mind, we can have some idea of what a counter movement is. A counter movement is a translation of a value variation of something in the consumer's mind. Reduced to one dimension we linked this to a consumer interest indicator. Then we can use a dimension to move our counter and another one to help to put it on the map. If age categories can be ordered, they are not the only element. Another alternative was proposed by Kim and Mauborgne (2000) with the buyer utility map. Kim and Mauborgne (2000) proposed a solution to identify where and how to present a new product or service. Their idea is to consider an innovation according to consumer utility. This map is based on six stages of buyer experience cycles and six utility levers (a set of variables) from the consumer's point of view. The crossing of these two sets forms the buyer's utility map (figure 2): "By locating a new product on one of the 36 spaces of the buyer utility map, managers can clearly see how the new idea creates a different utility proposition from existing products" (Kim and Mauborgne 2000).

For this we borrowed fundamental elements of the buyer utility map. For the six stages of buyer experience, we put them in connection with the purchasing process (Tyagi and Kumar 2004) and we added two stages: know and first use. Now we have at least eight stages of consumer experience cycles: (1) know and found, (2) purchase, (3) delivery, (4) first use, (5) use, (6) renew and reload, (7) maintenance and stowage, (8) disposal.

\begin{tabular}{|l|l|l|l|l|l|l|}
\hline Know the product & & Purchase & & Delivery & & First use \\
\hline
\end{tabular}

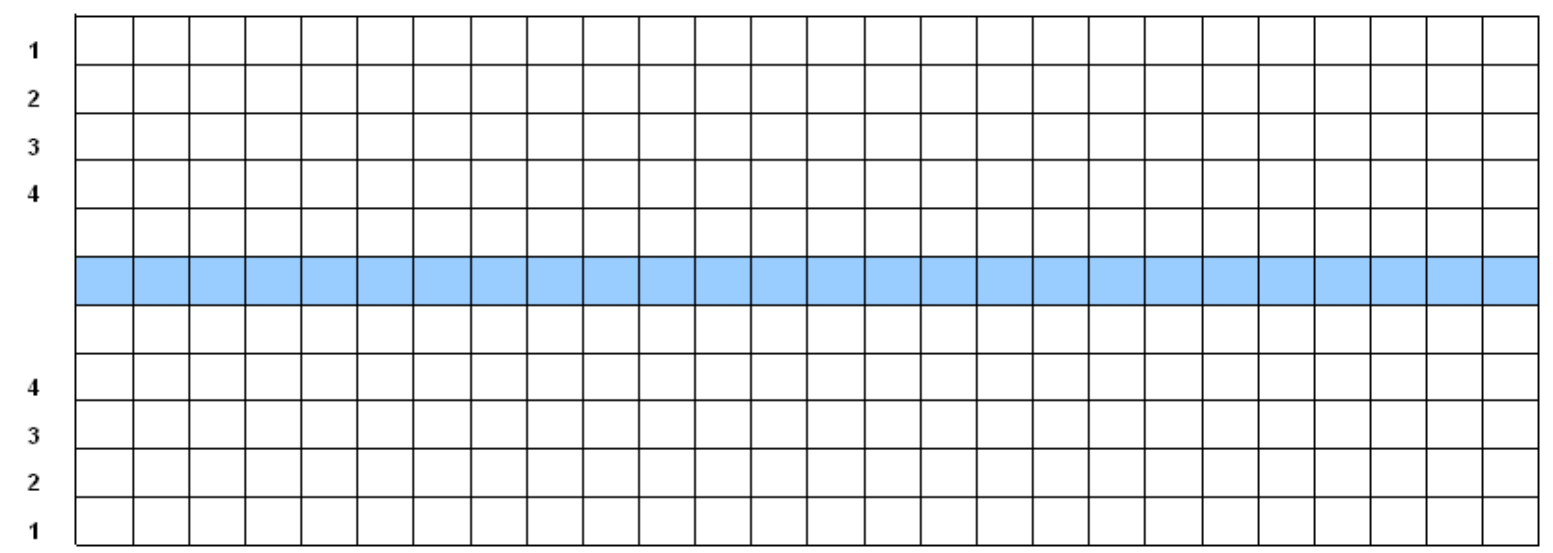

Figure 4: Part of blank square grid map for board wargame

The eight stages of the buyer experience cycle are a set of ordered parameters, and the consumer's interest for something is the second set of ordered values. Consequently, from the buyer's utility map, we transformed the user utility levers into consumer interest indicators and associate these with army unities. Then, we suggested estimating the value of one product or service utility by a user/consumer on a Likert scale from 0 to 4 . 0 represents the non- 
existent lever of the user or consumer perception. 4 represent the best satisfaction from the point of view of the user. To get symmetry, we can make 8 columns (from the 8 stages of consumer experience cycle) in which each company unit can be put in relation to a competitor unit. To use a set of consumer interest indicators by column, we divide them in functions of situations studied into 5 to 8 sub-columns and, for more visibility; we insert 1 or 2 columns between the 2 sets of sub-columns. To separate armies, we use 1 line between them, a line in the shape of river and we propose to board this line with 2 others, 1 for each camp. At the end we obtain a standard map on which army units can be put (see figure 4).

Then, we need to define some rules for the placement of the units and their movements. To be simple, in the point of view of one camp, we put a unit in a sub-column from left to right by beginning with the highest line, after we go to the second highest line, etc., with a displacement of some spaces to complete most of sub-columns with other lines. For the movement, we consider it as a result of a position phase and a combat resolution phase. A position phase is the phase in which a company puts its units on the map and proposes a rearrangement of them. A combat resolution phase is the phase in which we see the difference, for each column, between the total value (i.e. its strength) of a group of units of one army (put them in the sub-columns of the column) with the group of units of the other army in the same column. According to the result, the best group advances from 1 to 4 squares and the lesser group retreats symmetrically from 1 to 4 squares along the column. If the difference between two army groups is null or very weak there is no attack and retreat movement in this column. We propose this engagement resolution table (for 6 to 11 potential counters by column):

- 4 squares displacement if one group of units has a strength 4.1 or more higher than the competitor's group;

- 3 squares displacement if one group of units has a strength 2.4 - 4 higher than the competitor's group;

- 2 squares displacement if one group of units has a strength 1.5 - 2.3 higher than the competitor's group;

- 1 square displacement if one group of units has a strength $1.2-1.4$ higher than the competitor's group.

- no displacement if one group of units has a strength 1-1.1 higher than the competitor's group.

In function of the peculiarities of the situation (ground variations) and the value gap between the two groups of units, the umpire adapts his rule and decides how many squares the movement is. As for free kriegspiel, we can play the role of umpire or we can resort to an expert to play this role. The umpire estimates from the positions of units and other information like the importance of the interest lever vis-à-vis the supposed result of the engagement. This result can have three forms:

- each group of units doesn't move (equal fight);

- one group of units moves forward and the opposing group steps back;

- one group of units moves forward without opposition.

For a product clash map elaboration, the same_thing could be asked to the umpire about specificities of the battleground. The question can be asked for each column if movements on it are slower (a 1.6 superiority could be necessary to move from 1 square in place of 2 , for example).

Finally, we need to do a hypothesis about the sequence of events. In fact, in classical board games, each gamer player moves his pieces and calculates potential effects. When the game turn is finished and a new one begins, this is repeated until the end of the game. This is easy, but if we want to transpose some variables for a market with the aim of having a better understanding of competition for a specific type of product, this supposes an equivalent sequence of events. Thus, when we consider a battle for a product, we need to consider what the events are and if it seems logical that they form a sequence. Position and movement phases are realized with regard to the last position for each column. Then the product value scale is moved in function to the movements previously realized.

Finally, we obtain a system which allows us to confront estimations of two products or services equivalent of the consumer's points of view to a representation which results a board wargames analogy. Even though we only have linear movement by column, we can try to consider attack and defence warfare manoeuvre alternatives with this system.

\subsection{Inspiration from attack and defence ma- noeuvres}

The marketing warfare analogy was made from a war analogy and in some cases from battle analogies. To propose a wargame map of marketing situations, we thought that we would have to realize it in the same way. We looked for some historical battles in order to base our consideration on a visual analogy system. In fact many known battles have begun with a river separating two armies. We have found eight of them which illustrated eight kinds of marketing warfare attack or defence manoeuvres. The battles selected are: Granicus River (334 BC), Trebbia (218 BC), The Sabis (57 BC), Mohi (1241), Yamazaki (1582), Leuthen (1757), Austerlitz (1805) and Shiloh (1862). Of course features of 
unconventional attack or guerrilla warfare for maneuver considerations are such that we won't treat them with our proposition. The same problem arises for isolation attack and pre-emptive strikes. Thus, we have tried to consider a typical example for each one, attack or defence:

- Frontal attack: at the Battle of Granicus River (334 BC), in a narrow passage where the Persian army couldn't deploy its numeric superiority; Alexander the Great army charged with a bigger quality of cavalry and heavy phalanx infantry and initially defeated the Persian center after which the Persian army retreated.

- Flank attack: at the Battle of Yamazaki (1582), with as front line the Enmeiji River, Toyotomi Hideyoshi (the Japan's second great unifier) blocks his enemy Akechi Mitsuhide, fights adverse right flank with a local superiority and after this maneuver surrounds him.

- Bypass attack: at the Battle of Mohi (1241), separated by Sajo river, the Mongol army attacks the Hungarian army at the bridge of Mohi. Meanwhile many others Mongol troops directed by Subutai cross the Sajo river to the south of the bridge of Mohi where nobody waits them. After they attacked the Hungarians' rear flank.

- Encirclement attack: at the Battle of Trebbia (218 BC), after some provocations and having hidden some of his cavalry in the upstream to the Trebbia river, Hannibal waits the assault of the roman army which crosses the river. Then Hannibal's cavalry which isn't hidden attacks the roman army flanks and his hidden cavalry charges the roman rears.

- Counter offensive: at the Battle of the Sabis (57 BC), Caesar strengthens his camp to stop the frontal assault of Belgium tribes. Afterwards he counter-attacks, defeats his enemies and takes their camp.

- Mobile defence: near Leuthen (1757), an important Austrian army crosses the Schneidnitz River to fight the Prussians. Frederic the Great with half as important an army, but with a better mobility, divides his army in two groups, north and south, to fight the Austrians. After a withdraw feint, he brings his north army quickly to the south to get a superior position and then, repels and defeats the Austrian army.

- Flank positioning: at Austerlitz (1805), Napoleon's army leaves the Pratzen plateau Heights to align back to the Goldbach Brook apparently exposing a weak right flank to his enemies. But, when Prussians and Russians leave the Pratzen heights for attacking, the right flank of their army is exposed to all of the French army. Then, the Great Army rein- forces its right flank and engages in a general assault and defeats the enemy.

- Tactical withdraw: at the Battle of Shiloh (1862), the Union army is surprised by the Confederate army and moves back to a second line to defend itself, leaning on two gunboats on its flank. The Confederates are stopped at this level and after a day of confrontations, General Grant reinforcing forces cross back to the Tilman Creek and push away the enemy.

The major part of this development could be represented with a simple map. First, frontal attack, counter offensive and tactical withdraw can be represented with no modifications. Second, flank attack needs to establish the superiority for a group of units and an oblique or rotational movement directed to an enemy group of units adjacent to their column. For this, it seem necessary that the aggressor's group of units is superior to his opponent's group of units in its column and that a link between its column and the adjacent column including the target group for flanking attack can be establish in the consumer's mind. Third, the bypass attack needs a surprise effect on the battleground. To make it possible, we have added another particular stage between two columns. From the consumer point of view, we estimated a new column: divert and propose others functionalities, could be a solution to represent the bypass attack. At the moment, we have chosen to put it between stages (6) renew and reload and (7) maintenance and stowage. This particular stage creates a space in the battleground of the shape of a lake. For our consideration, for a company developing a product from a standard, innovation by addition of new functionalities is always a possibility but risky endeavour. If our complementary solution is not appreciated by customers, our army can't cross the lake. The lake underlines this risk and shows explicitly where a bypass attack can be realized. Fourthly, the encirclement attack and flank positioning defence are from our point of view variations of combinations between the attack and the defence above.

We propose according to the case and the context to move units from 1 to 3 squares of movement. All of these movements are good. Later, if a relation can be established between two buyers' experience where a group of units is in the opposite camp, then one has to be afraid of a flank movement in the invaded camp. Some units can then be turned to signal the flank movement.

\section{A product study: Example of market battle by board wargame display}

To illustrate our proposition, we show a possible interpretation of a home video game console battle between Sony and Nintendo. This illustration can 
help to explain our methodology. The battle began in 1989 when Nintendo breaks the home console game development partnership with Sony. In December 1994 Sony answers back with Playstation 1 on the Japanese market. From this moment, the battle between Sony and Nintendo implied 7 game consoles: Super NES (Nintendo Entertainment System), Playstation1 (Sony), Nintendo 64 (Nintendo), Playstation2 (Sony), Game Cube (Nintendo), Playstation3 (Sony) and Wii (Nintendo). For this information we did a deep interview with 4 people who bought at least 4 of the consoles and know the others. In this specific case, only the battle for the know the product, (2) purchase, (3) delivery, (8) maintenance and storage and (9) disposal are less relevant. We colour them in grey and the others in green to mark the differences.

Now, we need to design counters. We know that there are two counter owners: Nintendo and Sony. We propose to use a square counters type. The first information on the counter is its owner, and the second one is the consumer interest parameter linked to it. The owner will be represented by its name, a colour and a specific image. Nintendo's colour will be white and that of Sony, red. For the images, we take the Playstation logo for Sony and

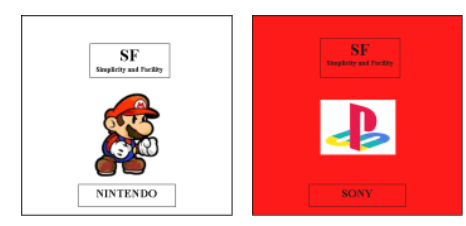

Figure 5: Information display on two counters linked to simplicity and facility parameter

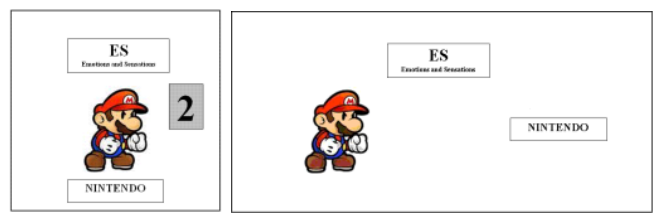

Figure 6: Two others possibilities to indicate the double value of a parameter (size * 1.5)

French market could be interpreted.

\subsection{Map and counter elaborations}

We know that it is the situation of a market which we have to represent: the French market of game consoles between 1994 and 2010. First, we adopt the consumer experience process to determine columns of the map. We add the column: divert and propose other functionalities. We have at this moment 9 columns. We know which shape of representation we are going to obtain. Then, we begin to design counters. Second, we need to determine which consumer interest parameters are relevant for this product study. From the list of user interest levers, we did some brainstorming and identified 9 consumer interest parameters: (1) simplicity and facility, (2) autonomy and adaptability (in the variations of context), (3) risk perception, (4) emotions and sensations, (5) well being, (6) cost, (7) trend or tradition, (8) quality and reliability, (9) variety of choice. With these 9 consumer interest parameters, we propose 6 sub-columns by column plus one other sub-column between each column to reduce visibility problems. Correspondingly, to obtain the value graduation and the symmetry between the two armies, we separate them for the first turn by the front line river. Third, the question of the ground variations is posed. Has each column the same importance for the French game console consumer? After a discussion, we decide that columns: (1) for Nintendo the most known personage for Nintendo, i.e. Mario (figure 5). The consumer interest parameter will be represented by its abbreviation in capital letters (for instance: SF for simplicity and facility) followed-up by its complete expression with a smaller font size. About ground variations, we need to ask about the consumer interest parameters, as some of them are more important than others. The response is yes for: (4) emotions and sensations and (9) variety of choice. We decide that these two parameters are twice as important as the others. Now, we have three choices from which to design these particular counters:

- write a strength indicator to show its double value (figure 6);

- use a double size counter to indicate its double value (figure 6);

- double the counter number for these parameters.

We make the third choice. Then, we ask ourselves if some other information should be displayed on the counters. One could be the value at a given moment of this parameter, but we decide that it is not necessary for the battle representation. Our choices of counter design are then completed. 


\subsection{Information gathering}

When we have determined counters and columns for the Game, we can develop some complementary rules and scenario or directly collect important information for the progress of the game. In our case study, we need to have, for each of the 7 game consoles, an evaluation on a scale from 0 to 4 and 9 points of view (our column categories) and 9 parameters (counters categories). We have at the moment 7 charts to complete. We could develop other charts for the estimation of one console at a moment vis-à-vis the competitors' consoles, but we think it's already implicitly present in our 7 charts. Thus this reduces the number of questions to ask. Then each player completes his charts. An average estimation is calculated by rounding off.

\subsection{Rules and scenario development}

First, we must decide on the sequence of events. We make the decision that each battle event is linked to the introduction of a new game console on the market. We suppose that it is reasonable to consider that these types of events can form a sequence. These events will help us determine the number of game turns. From information retrieval, we identified on French market, 5 turns for this battle:

1. 1995, Sony presents Playsation 1.

2. 1997, Nintendo responds with Nintendo64.

3. 2000, Sony proposes Playstation2.

4. 2001, Nintendo responds with GameCube.

5. 2006, Playsation 3 and Wii are on the market.

Each turn includes a game sequence. For our development we adopt a game sequence in 3 steps: (1) companies put their counters, (2) by column, unit's strengths are compared, (3) movement phase is realized in relation to the strength estimation.

Next, two questions can be asked, at the first turn who has the initiative and is one of the two compet- itors in a defence position? If the answer to the last question is yes, must we have some special rules for this turn? In our example, we decided that there is no real initiative. But, concerning the defence position, we think that Nintendo occupied the ground some time before Sony and this is why Nintendo has some advantage at the first turn. Then, for each group attack by the competitor, as strength estimation, we add implicitly the equivalent of one level 4 counter.

At the end one technical problem must be solved. What can we do if the number of counters on the same line of a column is up to 6 (number of sub-columns)? First, we can use one subcolumn to separate columns. Second, since we have two counters in double numbers, so we can pile them up in this case. In this last case, a small interval between the counter in the background and the counter in the foreground will indicate two counters in this position.

Now we can run the Battle game representation.

\subsection{Representation of the home video console bat- tle}

Turn after turn, we can display information in the shape of a tactical board wargame. Figure 7 presents a global map with an initial position of the competitor in the mind for the test group. To present other turns and game sequences, we just focus on 4 green central columns: (4) first use, (5) use, (6) renew and reload and (7) divert and propose others functionalities (figure 8). Let's form ours charts; the other columns bring no modification in the battle situation. In addition, the size of the real map is too big to clearly display all information in this paper.

So figure 8 represents a counter position after the movement resolution at the end of turn 1 . 


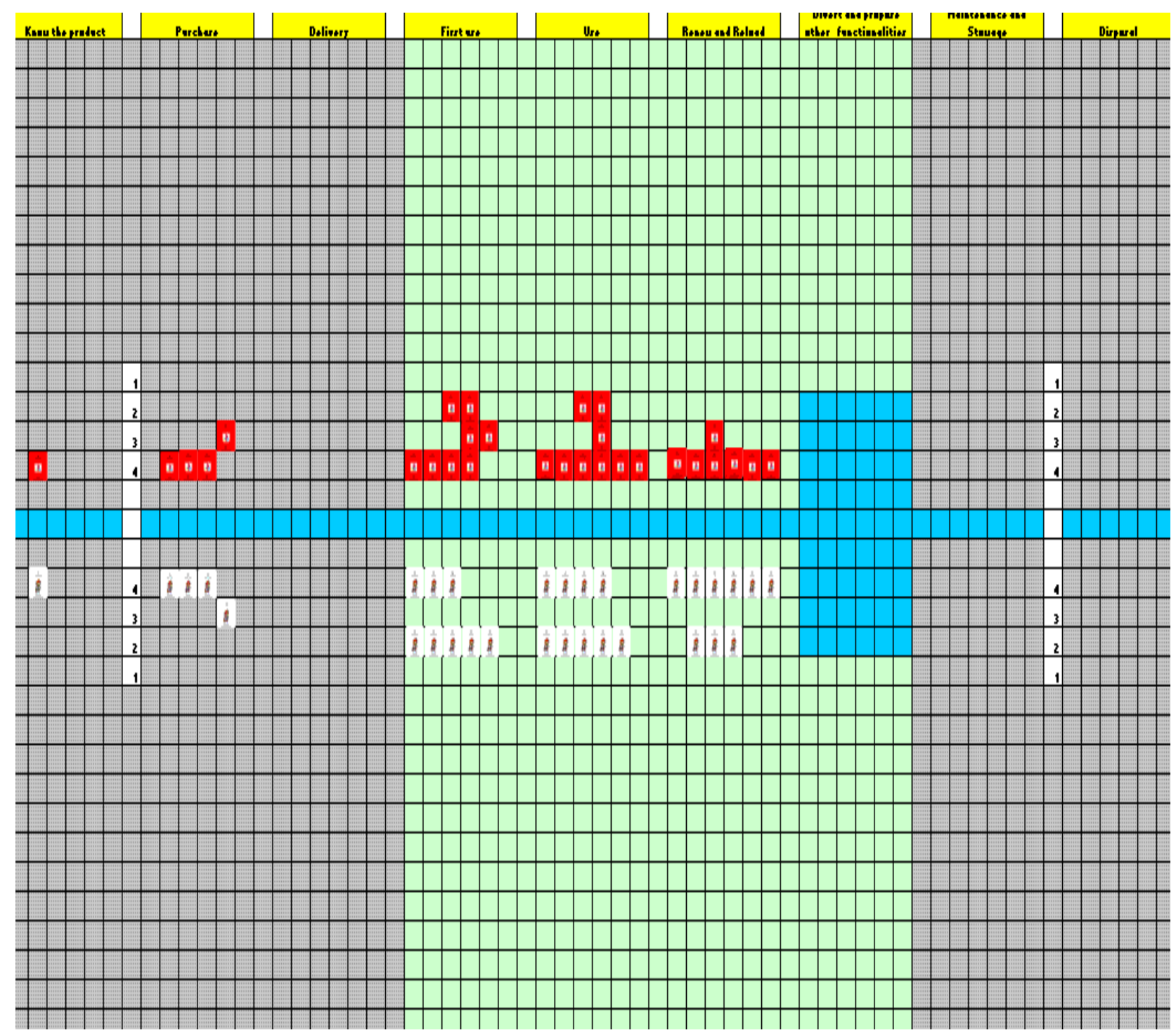

Figure 7: First turn, first game sequence, Sony attack Playstation 1 against Nintendo Super Famicom (before movement, map scale 1/5) 


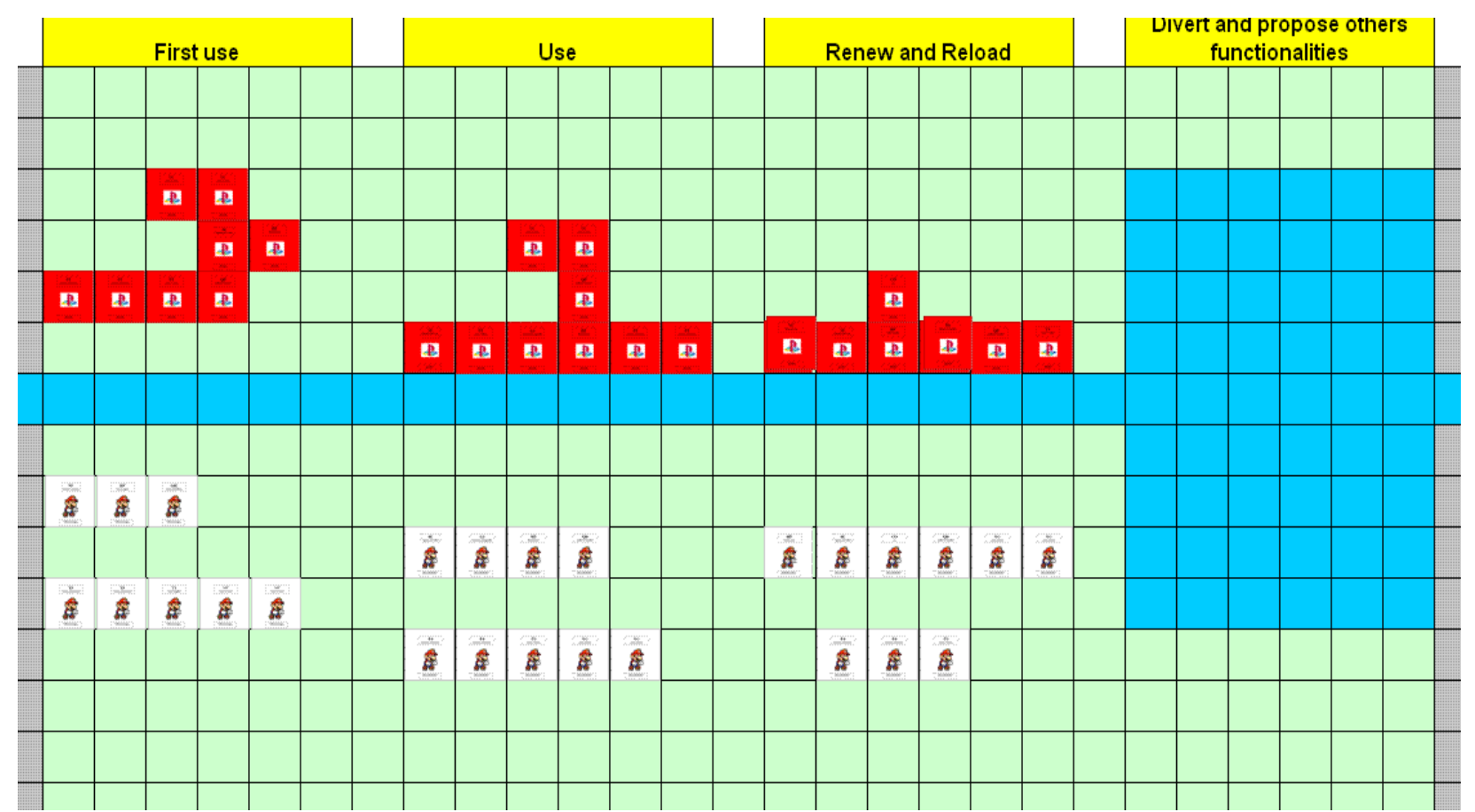

Figure 8: First turn, third game sequence, Sony attack Playstation 1 against Nintendo Super NES (after movement, map scale 1/2)

Figure 9 displays the arrival of the Nintendo64 console versus Playstation1. In this figure, the movement sequence is completed. We can see the failure of the counter attack and the retirement of Nintendo64 units.
In figure 10 , we note progressive losses of ground for Nintendo confronted with Playstation2. We see the units of Sony crossing the lake to bypass the attack, linked particularly to the possibility for this console to read DVD.

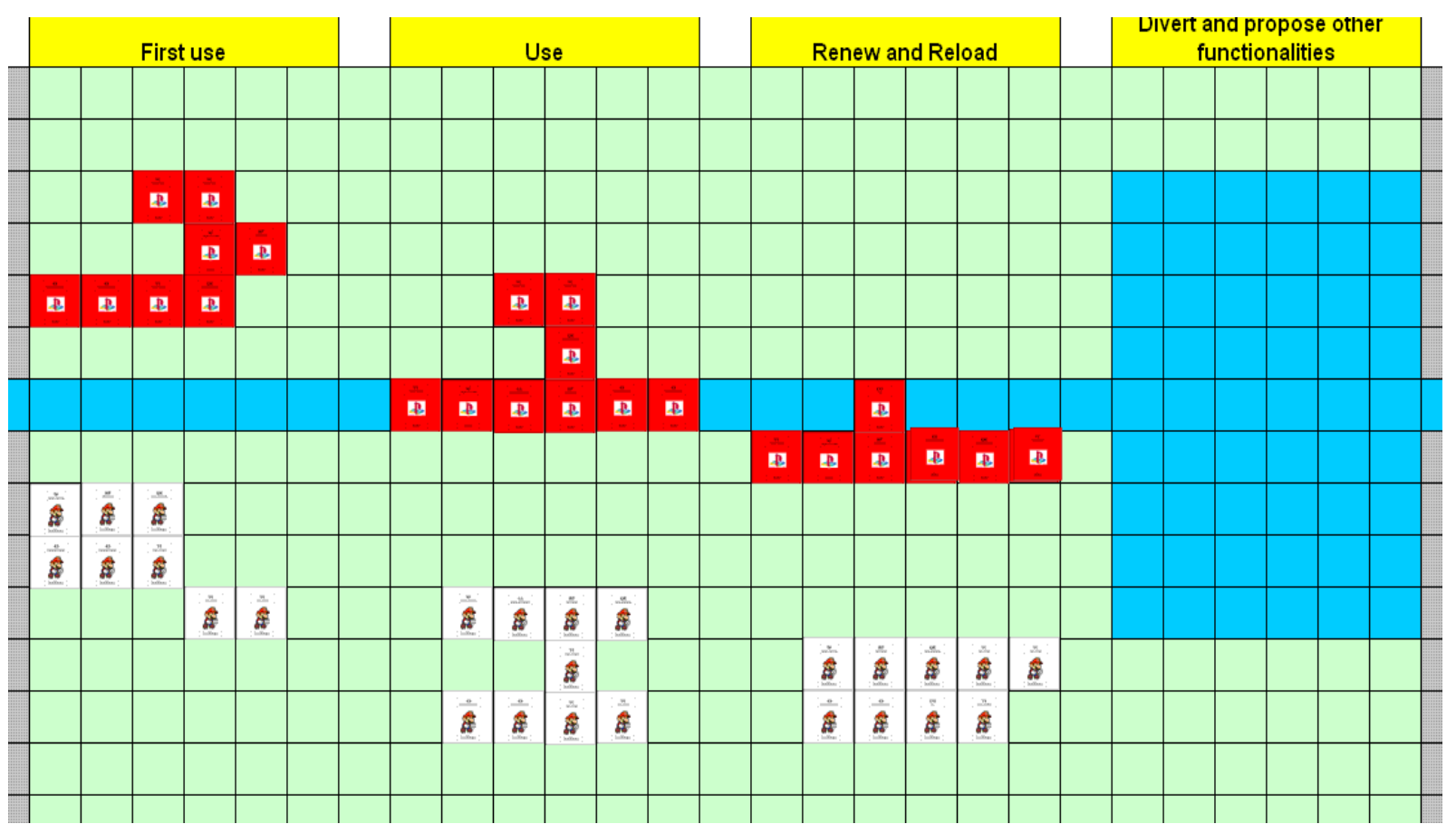

Figure 9: Second turn, third game sequence, Nintendo 64 response to Playstation (after movement) 


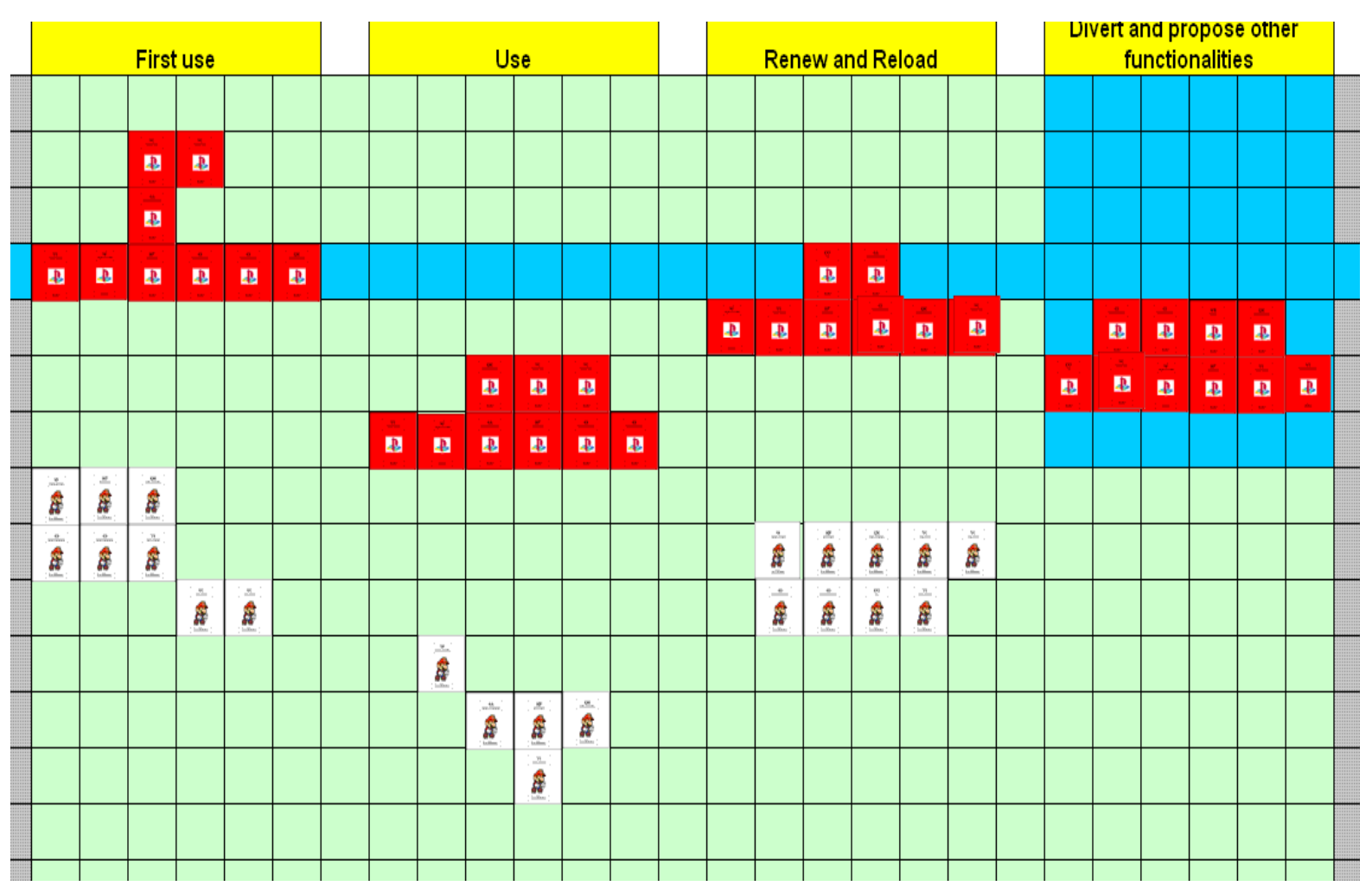

Figure 10: Third turn, third game sequence, Playstation 2 against Nintendo 64 (after movement)

Figure 11 shows Nintendo's response to Playstation2 with GameCube. Again we see the defeat of Nintendo's units against Sony's solution. units in column "renew and reload".
This figure also shows the Sony encirclement attack on the group of Nintendo.

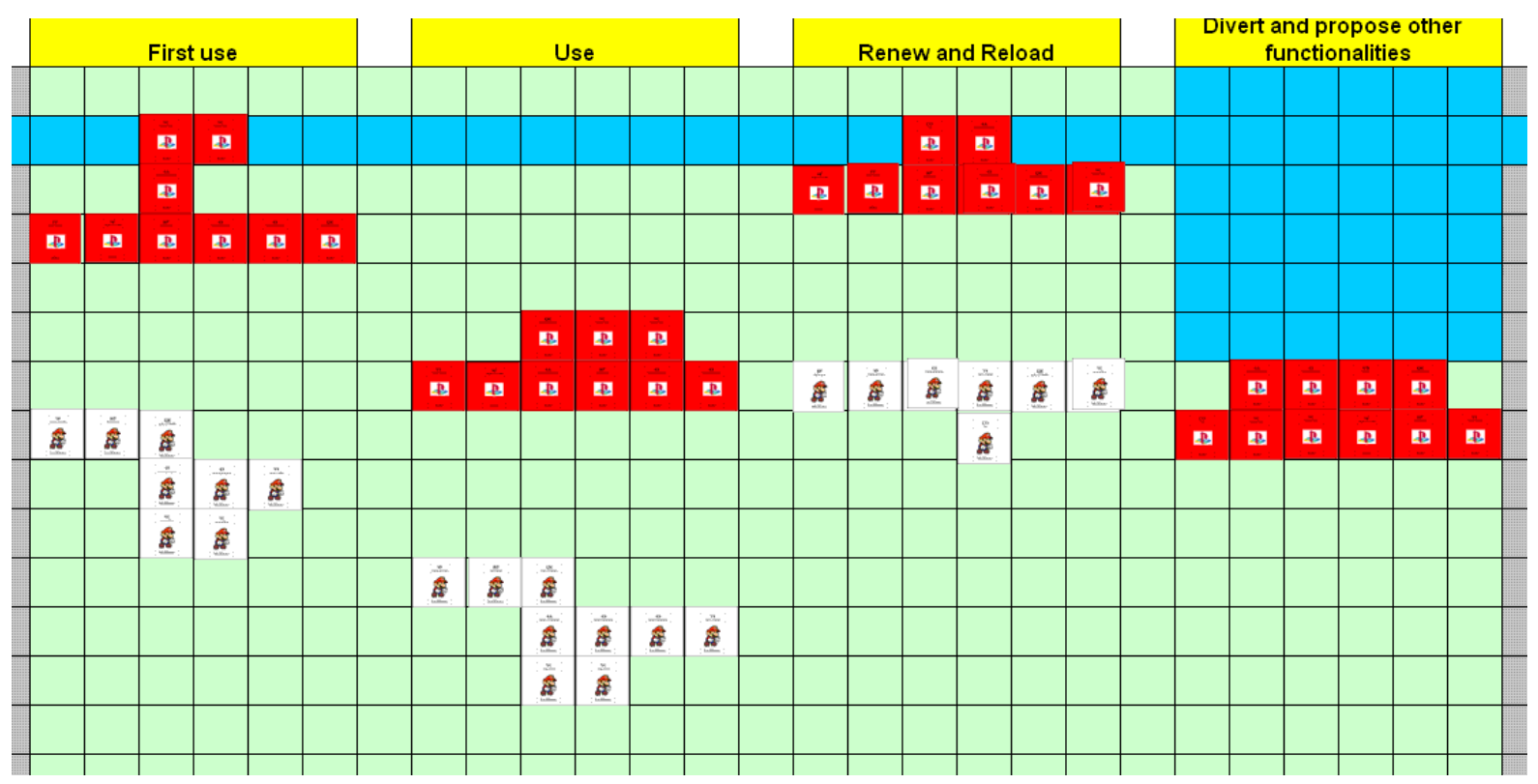

Figure 11: Fourth turn, third game sequence, Game Cube against Playstation 2 (after movement)

Finally, figure 12 represents the simultaneous arrival on the market of Playstation3 and the Wii con soles. We see the Nintendo counter offensive for each column. The occupation of column seven by 
Nintendo is explained by the possibility to use Wii for fitness. For Sony, this column is a continuation of the Playstation2 solution with the integration of a Blue-Ray/DVD reader in Playstation3.

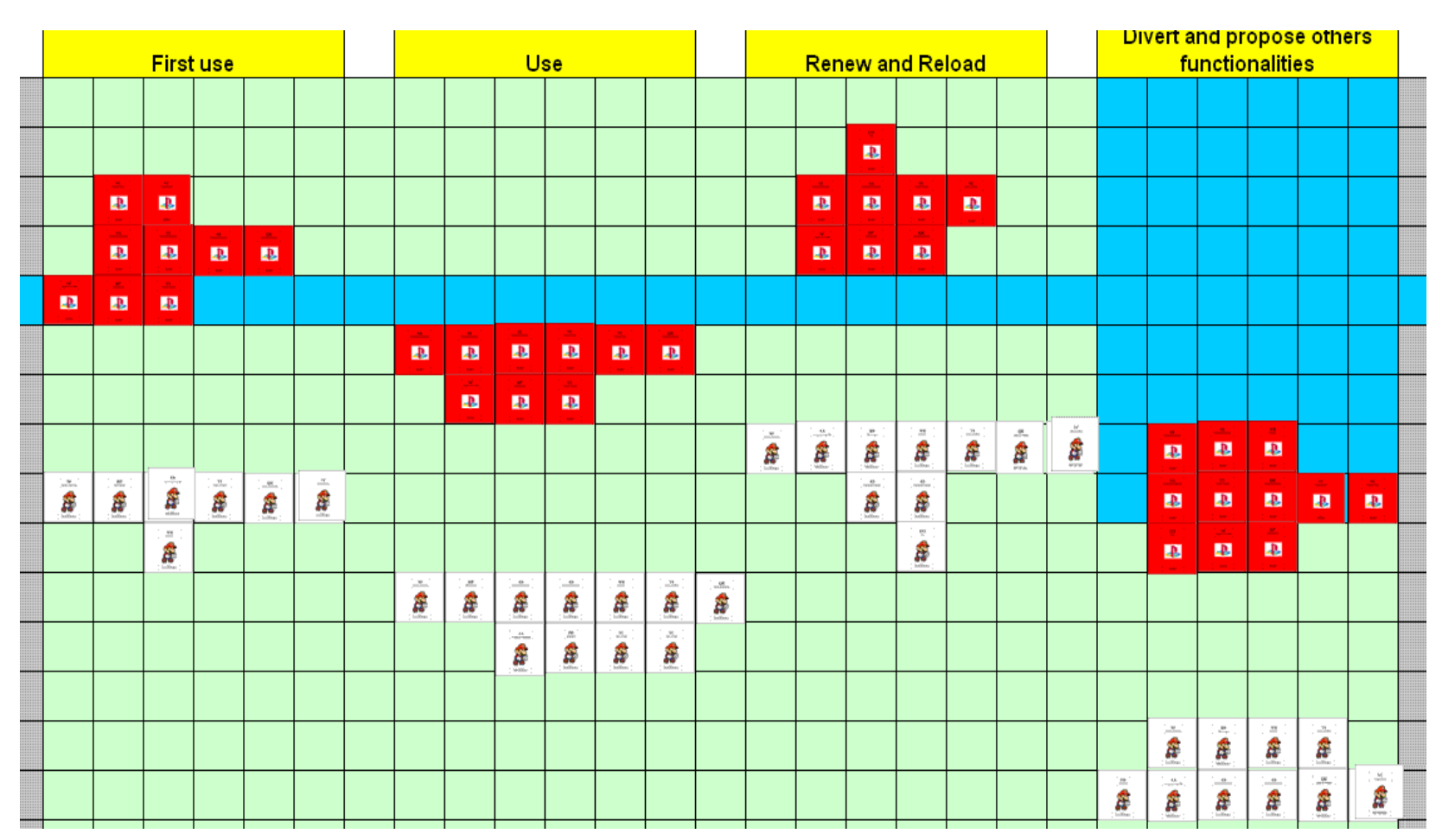

Figure 12: Fifth turn, third game sequence, Playstation 3 against Nintendo Wii (after movement)
We can now also see the potential risk for Sony, to suffer a flank attack on the column: divert and propose other functionalities. 


\subsection{Possible interpretations of the home video game console battle}

With some statistics from the year 2001 on game consoles sales on the French market ${ }^{3}$ and in function to the marketing warfare maneuver link, we can propose some interpretations based on this information visualization method.

First, we can see, with figures 8 and 9, the mutual frontal engagement between Sony and Nintendo game consoles. With Playstation2, we can see a bypass maneuver by Sony. Figure 10 illustrates it and the statistics of the year 2001 in France for market shares show: Playstation2, 19\%, Nintendo64, 2\%. The Nintendo response with GameCube doesn't try to stop the Sony bypass attack. The statistics for these consoles on the French market for the years 2003 are: Playstation2, 30\% and GameCube, $8 \%$. The real counter attack by Nintendo is realized with Wii. As for Playstation in front of the Nintendo64; for each central column implied by the Sony assault, Nintendo is the better option. French market shares in 2009 for Playstation 3 are 20.8\% and for Wii, 27\%. This is a general counter attack. The reduction of Nintendo's response delay with this last console persuades us that the GameCube was introduced on the market as a tactical withdrawal or a flank positioning. We also notice that at this moment and in a similar situation, consecutive failures of the Sega consoles (MegaDrive, SegaSaturn and Dreamcast) in front of the Playstation1 and 2 , Sega choose a strategic withdrawal. The company stopped game console development and now proposes video games for others consoles instead. Consequently, and with this example, it seems that according to the logic of marketing warfare, the flanking attack has a more important impact than frontal attack, even though the difference between the forces used is significant. Indeed for bypass threat (figure 10 and 11), differences between the French market shares are respectively $17 \%$ and 22 $\%$ for Playstation2 vs Nintendo64 and Playstation2 vs GameCube. By comparison, when the Nintendo Wii counter attack is realized, it is similar to a frontal attack and the French Market difference is $6.2 \%$ for the year 2009 .

\section{Conclusions and perspectives}

We have investigated some fundamental principles of marketing warfare to see specifically what kinds of maneuvers can be used to defend or take a certain market. In parallel, we have presented military wargames and its history to ease understanding of the fundamentals in this area of study. The reason is that tactical wargames propose some solution to recreate a specific battle with the use of army maneuvers. Since we did not find a visual business wargame solution for our problem in the literature, we decided to develop one. For this, our approach

\footnotetext{
${ }^{3}$ Agence Française pour le Jeu Vidéo: http://www.afjv.com
}

is based on current tactical board wargames for civilians. We have presented all components to be found and an equivalent for each component in order to generate a product clash map. Then we introduced the tokens of the game, as they are important variables for the product's potential consumers. To define battle orders, we used an ordered set of process steps in correlation with an estimation scale of consumer interest for the product concerned. With these elements, we reconsidered a classical tactical maneuver as defined by a market warfare situation for our battle map system. We concluded than most tactical maneuvers could be interpreted with this system. Finally, we have shown how to interpret a market battle with this kind of information display. To prove this we built a wargame to represent the battle of a home video game console on the French market from 1994 to 2009. It showed that a parallel could be made between tactical maneuvers on the map and the statistics of sales for this market at a given time. Thus the usefulness of the game seems to have been confirmed.

Future research: We now continue ours experimentation to make board wargame in order to simulate other market examples. We hope to develop a software dedicated to this, with an additional possibility to transform a square grid map into a hexagon grid map to improve the connection with tactical wargame maps. In our opinion, this information visualization tool permits one to perform competitive intelligence with the possibility to add substantial value to the organization. Another advantage of this methodology is to extend the question about the company environment to identification of threats and market opportunities linked to a service or a product. In the continuation of this idea, we think that the information display can help to_make decisions about innovation strategies as well. For instance, decision-makers can identify where the major impact of a product could be. Then, in connection with a list of parameters (equivalent to a unit in our representation) considered as important on the map, the company can define specifications for an innovation team dedicated to developing the new product. Thus, we hope to extend our work to contribute to the area of innovation sciences too.

\section{References}

Andlinger, Gerhard R. 1958. Looking Around: What Can Business Games Do?. Havard Business Review 36(4): 147-152.

Besson, Bernard et al. 2010. Méthodes d'analyse appliquées à l'Intelligence Economique, Livre Blanc II. Poitier : ICOMTEC.

http://www.inovdia.fr/mediatheque/Bibliotheque/B usiness $\% 20$ Model\%20et\%20Intelligence\%20Econ omique/Guide_IES.pdf

Bose, Ranjit. 2008. Competitive intelligence process and tools for intelligence analysis. Industri- 
al Management \& Data Systems 108(4): 510528.

Boutin, Michel. and Parlebas, Pierre. 1999. La métromachie ou la bataille géométrique. Board Game Studies 2: 80-103.

http://history.chess.free.fr/papers/Boutin\%20Parleb as\%201999.pdf

Cares, James and Miskel, Jim. 2007. Take your third move first. Harvard Business Review 85(3): 20-21.

Kim, Chan W and Mauborgne, Renée. 2000. Knowing a Winning Business Idea When You See One. Havard Business Review 78(5): 129138.

http://www.fjxedu.gov.cn:8010/TempResourceFiles /1918088175.pdf

Dunnigan, James F. 2000. Wargames Handbook, Third Edition: How to Play and Design Commercial and Professional Wargames. San Jose: Writers Club Press.

Durö, Robert and Sandström, Björn. 1987. The basic principles of Marketing Warfare. Chichester: John Wiley \& Sons.

Faria, Anthony J. and Nulsen, Ray. 1996. Business simulation Games: current usage levels: A ten year update, Developments In Business Simulation \& Experiential Exercises 23: 22-28.

http://sbaweb.wayne.edu/ absel/bkl/vol23/23ad.pdf

Fuld, Leonard. 2003. Be Prepared: The Future looks a lot less Uncertain with the right Early Warning System. Harvard Business Review 81(11): 20-21.

Gilad, Benjamin. 2009. Business War Games: How large, small, and new companies can vastly improve their strategies and outmaneuver the competition. Franklin Lakes: Career press.

Gilad, Benjamin. 2003. Early Warning: Using Competitive Intelligence to Anticipate Market Shifts, Control Risk, and Create Powerful Strategies. New York: Amazon.

Herman, Mark, Frost, Mark and Kurz, Robert. 2009. Wargaming for leaders: Strategic decision making from the battlefield to the boardroom. New York: McGraw Hill.

James, Barrie. 1985. Business Wargames. West Chilington: Chanctonbury Press.

Jenster, Per V. and Søilen, Klaus Solberg. 2009. Market Intelligence: Building Strategic Insight. Copenhagen: Copenhagen Business School Press.

Kalman, J. Cohen and Rhenman, Eric. 1975. The Role of Management Games in Education and Research. In Greenblat, Cathy S. and Duke, Richard D. ed., Gaming-Simulation: Rationale, Design and Application, New York: Sage Publication, pp. 233-269.

Kotler, Philip and Singh, Ravi. 2001. Marketing warfare in the 1980s. Marketing: critical perspectives on business and management 3: 411428.
Kurtz, Jay. 2003. Business wargaming: simulations guide crucial strategy decisions. Strategy \& Leadership 31(6): $12-21$.

http://www.kappawest.com/WP_Strategy\%20\%26 \%20Leadership\%20-\%20BW\%20ARticle.pdf

Kurtz, Janel and Schuler, Drue K. 2008. Competitive intelligence at Procter \& Gamble: A case study in trade secrets. Journal of Legal Studies Education 21(1): 109-149.

Lundvall, Benkt-Ake. 2010. National Systems of Innovation: Toward a Theory of Innovation and Interactive Learning. London: Anthem Press.

Oriesek, Daniel F. and Schwarz, Jan Oliver. 2008. Business Wargaming: Securing Corporate Value. Hampshire: Gower House.

Patrick, Stephen B. 1977. The history of wargaming. In Berg, Richard H., Ryer, Robert J. and Simonsen Redmond A. ed, Wargame design: The History, Production and Use of Conflict Simulation Games. Strategy \& Tactics staff study Nr. 2, Simulations Publications Incorporated. New York, pp. 1-40.

Perla, Peter P. 1990. The art of Wargaming. Annapolis: Naval Institute Press.

Pyzdek, Thomas and Keller, Paul A. 2003. The Six Sigma handbook: a complete guide for green belts, black belts, and managers at all levels. New York McGraw-Hill.

Ries, Al and Trout, Jack. 2006. Marketing Warfare. New York: McGraw-Hill.

Schwartz, Robert G. and Teach, Richard D. 2002. The E-commerce game: as strategic business board game. Developments in Business and Experiential Learning 29: 195-207.

http://sbaweb.wayne.edu/ absel/bkl/.\%5Cvol29\%5 C29bi.pdf

Simonsen, Redmond A. 1977. Image and System: Graphics and Physical Systems Design. In Berg, Richard H., Ryer, Robert J. and Simonsen Redmond A. ed, Wargame design: The History, Production and Use of Conflict Simulation Games. Strategy \& Tactics staff study Nr. 2, Simulations Publications Incorporated. New York, pp. 56-88.

Trot, Paul. 2008. Innovation management and new product development. Edinburgh: Prentice Hall.

Tyagi, C.L. and Kumar, Arun. 2004. Sales Management. New Delhi: Atlantic Publishers and Distributors.

Weaver, Charles N. 1991. TQM: a step-by-step guide to implementation. Milwaukee: ASQC Quality Press. 